\title{
Oxymoron, a Non-Distance Knowledge Sharing Tool for Social Science Students and Researchers
}

\author{
${ }^{1}$ Institut Universitaire Kurt \\ Bösch (IKB) \\ Bramois \\ ${ }^{2}$ Université Coopérative Sans \\ Distance du Roannais (UCSDR) \\ 13 rue Brison \\ 1950 Sion, Switzerland \\ 42300 Roanne France \\ camille.bdehaan@ikb.vsnet.ch \\ gchabre@avo.fr \\ francis.lapique@epfl.ch \\ gil.regev@epfl.ch \\ alain.wegmann@epfl.ch
}

Camille Bierens de Haan ${ }^{1}$, Gilles Chabré ${ }^{2}$, Francis Lapique ${ }^{3}$, Gil Regev ${ }^{3}$, Alain Wegmann ${ }^{3}$

${ }^{3}$ Swiss Federal Institute of

Technology (EPFL)

EPFL-ICA

CH-1015 Lausanne, Switzerland

\begin{abstract}
Oxymoron is a World Wide Web based knowledge capitalization and sharing tool that was conceived and developed by a multidisciplinary team, comprised of adult education and distributed systems professionals from France and Switzerland. Oxymoron's aim is to support and facilitate the work of students and researchers in social science by providing them with a system where they can contribute and obtain knowledge about the relevant readings in their fields of interest.
\end{abstract}

\section{Keywords}

Groupware, Knowledge Management, Organizational Learning, WWW, Social Sciences, Bibliography, WWW, Methodology of research, Reading cards.

\section{INTRODUCTION}

Oxymoron, a rhetorical figure in which incongruous or contradictory terms are combined, as in "a deafening silence" and "a mournful optimist." From the Greek oxymoros, pointedly foolish: oxus, sharp + moros, foolish (American Heritage Dictionary 1991)

While paradox, humor, contradiction and a bit of gentle provocation are the ingredients of an oxymoron, the authors of Oxymoron have chosen this name mainly because new names are needed to name new realities. As paradoxical as a virtual reality, Oxymoron is a tool that not only facilitates distance research but also enables cooperative work and the tutoring of students and researchers.

Permission to make digital or hard copies of all or part of this work for personal or classroom use is granted without fee provided that copies are not made or distributed for profit or commercial advantage and that copies bear this notice and the full citation on the first page. To copy otherwise, to republish, to post on servers or to redistribute to lists. requires prior specific permission and/or a fee.

GROUP 99 Phoenix Arizona USA

Copyright ACM 1999 1-58113-065-1/99/11 _..\$5.00
The main idea behind Oxymoron is to create a user community of researchers through the capitalization of reading cards, which are an important and time expensive step in the most current methodology of research in social sciences. The concept of a reading card is central to the pedagogical approach described in this paper. Reading card was translated from the French expression "fiche de lecture". We derived the term reading card from the popular term of flash cards. Flash cards are used in schools to help students memorize facts. The Oxymoron reading cards are different from flash cards in the sense that they are mainly used to conceptualize knowledge and to exchange it between students. Also, like flash cards, reading cards are created by the students themselves rather than by the teachers or tutors [8].

This paper introduces a pedagogical approach to adult education and a tool developed to support that approach. We first present the origins and objectives of Oxymoron, its related pedagogy, and stakeholders. We then explore its structure, functionality and evolution. Finally, we explore the user interface and system architecture and end with a conclusion and future work plans.

The diagrams in this article were made using the Unified Modeling Language, UML [19]. We use UML to describe both processes [11] and system architecture [7].

\section{ORIGINS}

Oxymoron was generated during Gilles Chabré's 10 years experience tutoring working, non-university, adults in the social science fields. In the course of the research process, the students are required to read and are asked to realize reading cards. Until now, these cards were usually hand written, sometimes typed, (hopefully) lent to companions and always taken away when the process was completed. The need for a tool, which would make it possible to share bibliographical resources and make them available without 
distance and whenever needed, was evident: Internet made the dream come true.

The first encounter occurred virtually, on the Web, in early spring 1997. It brought together the educators who conceived Oxymoron and the engineers who implemented it. Subsequently, these people who didn't know each other, were active in different working structures, disciplinary fields, professions, and cultures, met in face-to-face meetings.

As it often happens, this original creation is due to the commitment of a number of passionate people. EPFL, Switzerland's top-level university for engineering, has highly acute technical expertise for which it is in search of social and cultural rooting. AFXB, (Switzerland and France) and UCSDR (France), two small associative structures active in the health care (a palliative care postgraduate education program within IKB, which is a small young Swiss university) and in the field of adult education in social science, respectively. IKB, as well as UCSDR, are directly interested in constructing open and distance learning tools for their students

After two years of work, the institutions became aware of the importance of this marginal founding and the trend is leading towards a formalization of the collaboration.

\section{Related Work}

It is interesting to position Oxymoron with regard to distance learning tools and bibliography management systems. In our view, Oxymoron is neither an encyclopedia, nor a library filing tool, nor a usual distance-teaching tool. It rather is a personal and inter-peer knowledge sharing and collaborative working tool. It provides personal choices and views on specific literature. Like distance learning tools, we place the students (or researchers) at the focal point of the system but we do not have course syllabus, modules, quizzes etc. Like bibliography management systems, we have a repository of references together with their quotes. But this repository is available through the World Wide Web and is self supported by the students through a principle of gift/counter-gift. The Oxymoron knowledge repository is not submitted to teachers' validation and is used mainly as a support for the narrowing down of the material to be read in view of the preparation of a thesis and for the identification of other researchers working in the same domain. The originality of Oxymoron resides in the combination of a precise methodology of research with a World Wide Web accessible tool and an interdisciplinary knowledge repository.

Oxymoron can be best positioned in the knowledge management category. Like other knowledge management tools such as Ackerman's Answer Garden [1] and British Telecom's Knowledge Sharing Environment [5]. Its objective is to link people with knowledge and with other people.

\section{OBJECTIVES}

The principal ideas behind Oxymoron are directed towards individual persons, as well as towards the community:

For individual persons:

- Facilitate identification and contact with other researchers on specific themes

- Facilitate finding of relevant literature and reduce wandering and exploration time

- Save and share personal readings

- Become familiar with publishing one's works and issuing critical comment to others

For the community:

- Create a networked community of researchers

- Create and share an interdisciplinary knowledge repository

- Share a collection of informal knowledge in the form of fine-grained annotations of the repository

- Promote non-distance learning ${ }^{1}$ and tutored pedagogy

Capitalization of knowledge is a serious problem for education and research institutions that want to create an institutional memory, most notably because researchers and students leave with their personal notes at the end of their project. The trace of their thinking trails [2] and construction processes are not retained by the institutions whose missions, by definition, go beyond those of its students. Oxymoron represents the possibility to save and accumulate the results of the works of successive classes of students and researchers and thereby create a "humus" made out of the accumulation and union of all this material.

The sharing of research works fits into the framework of the ongoing mutation of the knowledge economy: The creation of collective intelligence is one of its foundations and cooperative work is one of the most promising avenues for tomorrow's pedagogy [13]. Oxymoron offers, for adult students engaged in an education process leading to the creation of a thesis, the possibility of communicating to their peers the results of their exploration of the literature. In compensation for which, they obtain access to the works of all the other users of the tool.

Furthermore, Oxymoron encourages the publication and sharing of thought processes, in construction, by way of fine-grained annotation [12]. Annotations, by their potentially informal nature may capture what Conklin calls informal knowledge [4].

The constitution of a network of researchers is geared toward the need for distance learning, for networking

${ }^{1}$ Distance learning implies a flow of knowledge from a knowing center towards a learning periphery. Nondistance learning designates a networked flow of knowledge combined with a different pedagogy [22] 
cooperative partnerships in education, for changing the nature of pedagogy: in short, the need for formatting a new space for the emerging cyberculture that is already completely rebuilding our economy of knowledge.

Oxymoron is not a documentation center or a collection of validated works. It is a tool for sharing knowledge and research processes. In short, Oxymoron aims to preserve the paths rather than the goals. Oxymoron is not a library but a workshop where different tools are displayed, as well as various sketches at different stages of work. This workshop is precisely the place where actors and authors are expected and encouraged to meet.

Oxymoron functions under the principle of gift/counter-gift: one may get to the repository on condition that one has previously enlarged it. The student's benefit should be obvious: for 3 reading cards given in your field, you get access to at least $3 * \mathrm{n}$ reading cards in different fields, where $\mathbf{n}$ is the number of Oxymoron users. Every researcher knows what amount of saved time this represents, apart from comprehensive inter-disciplinary possibilities.

Oxymoron's intent is also to encourage publication and the exchange of ideas, stimulate cooperative work and train expression through writing.

\section{PEDAGOGY}

Oxymoron complies with and enhances a precise methodology of research defined by Quivy and Campenhoudt [21] that is broadly spread throughout the French speaking social sciences. Its structure unfolds like the different and successive stages of building a research (figure 1):

\section{- formulation of the research problem}

- analysis of state of the art (i.e. bibliographical exploration)

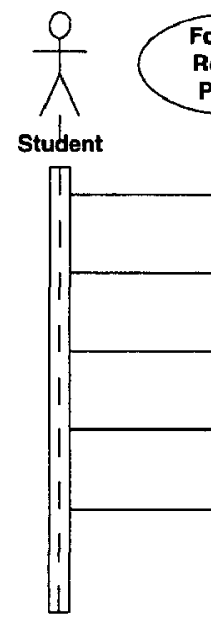

- hypothesis formulation (concept definition)

- field study

- theoretical interpretation

The formulation of a research problem enables the definition of a number of key words, which, in turn, function as markers allowing the identification of other researchers interested in the same topic and the finding of relevant titles and quotations in the knowledge repository.

Once they find the bibliographical entry they are looking for, users can see if other users have already added value to this particular book or article or if the title has just been signaled as being an important reference. A reading card is not meant to prevent the students from reading the authors in texto but to help them find the right people and the relevant ideas in relation to a number of specific themes.

Users in search of documentation will be able to narrow down the set of books they need to read and understand by walking through the reading notes made by other users.

Oxymoron's Glossary supports the hypothesis formulation (or concept definition) phase by displaying a number of sourced definitions. This is not only, generally speaking, indispensable to know what one is talking about in a research process, but also how the notion has recently been evolving. More precisely, it also helps in the construction of the field study tool allowing the singling out of the necessary dimensions, indicators and indices.

Once the field study has been conducted and the collected material classified, reading cards are again helpful in the construction of the theoretical interpretation. 


\section{STAKEHOLDERS}

Oxymoron is an extranet tool that any number of institutes can share to capitalize knowledge. Figure 2 shows the different stakeholders.

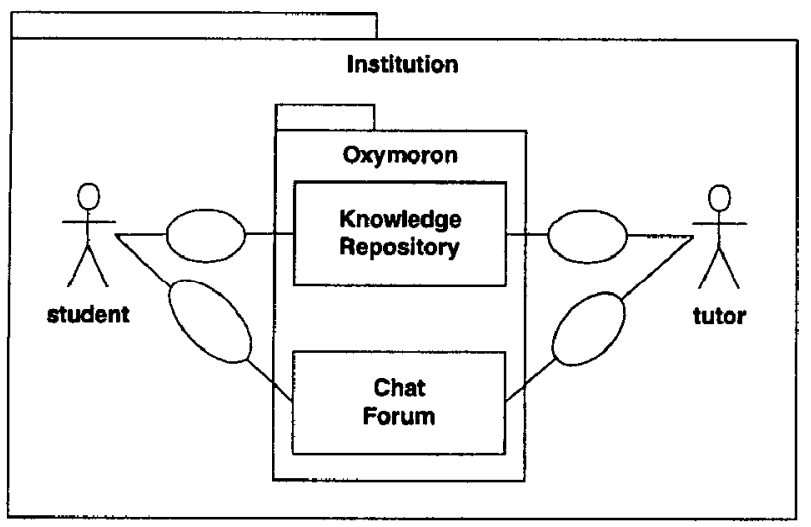

Figure 2. Oxymoron Stakeholders

\section{Institutions}

Institutional tutoring seems to be the indispensable condition to insure quality, as well as quantity, of content in the repository. An institution warrants not only a certain level of thought but also the amount of cards in a certain disciplinary field, which is the main source of interest for users.

The kinds of institutes that are likely to benefit from Oxymoron are adult education, higher education and research institutes.

Markus and Keil [16] found that the introduction of a new information system, even a well designed one, that is done without a business process reengineering is likely to fail. Thus, organizations should not contemplate adopting Oxymoron without analyzing their existing pedagogy and processes and the way the introduction of Oxymoron may change them.

Access to Oxymoron is granted through two conditions : a yearly registration fee - the amount of which is yet to be determined - and the nomination of at least one institutional tutor.

\section{Tutors}

Within an adult education institution, the Oxymoron tutor is in charge of introducing the students to the rules and benefits of Oxymoron and instructing them. He or she will also have to encourage participation and assist with the first procedures, and cope with the subsequent upsurging resistances and discouragements facing new technology. The tutor personally verifies the format of every student's first entries and delivers passwords as soon as the required amount of entries is completed. He or she may be joined without distance in case of a methodological or a technical problem. Once (or more, experience will show) a year, he or she will have to check the knowledge repository created by "his/her" students and do some "cleaning up" under supervision of a number of disciplinary experts.

Tutoring can also be done off-line, through face-to-face meetings and telephone calls. We have implemented the forum and chat services in Oxymoron to help tutors to carry out their tasks and offset the cost of traveling and phone calls. But we must admit that our students are not yet really familiar with these means of communication.

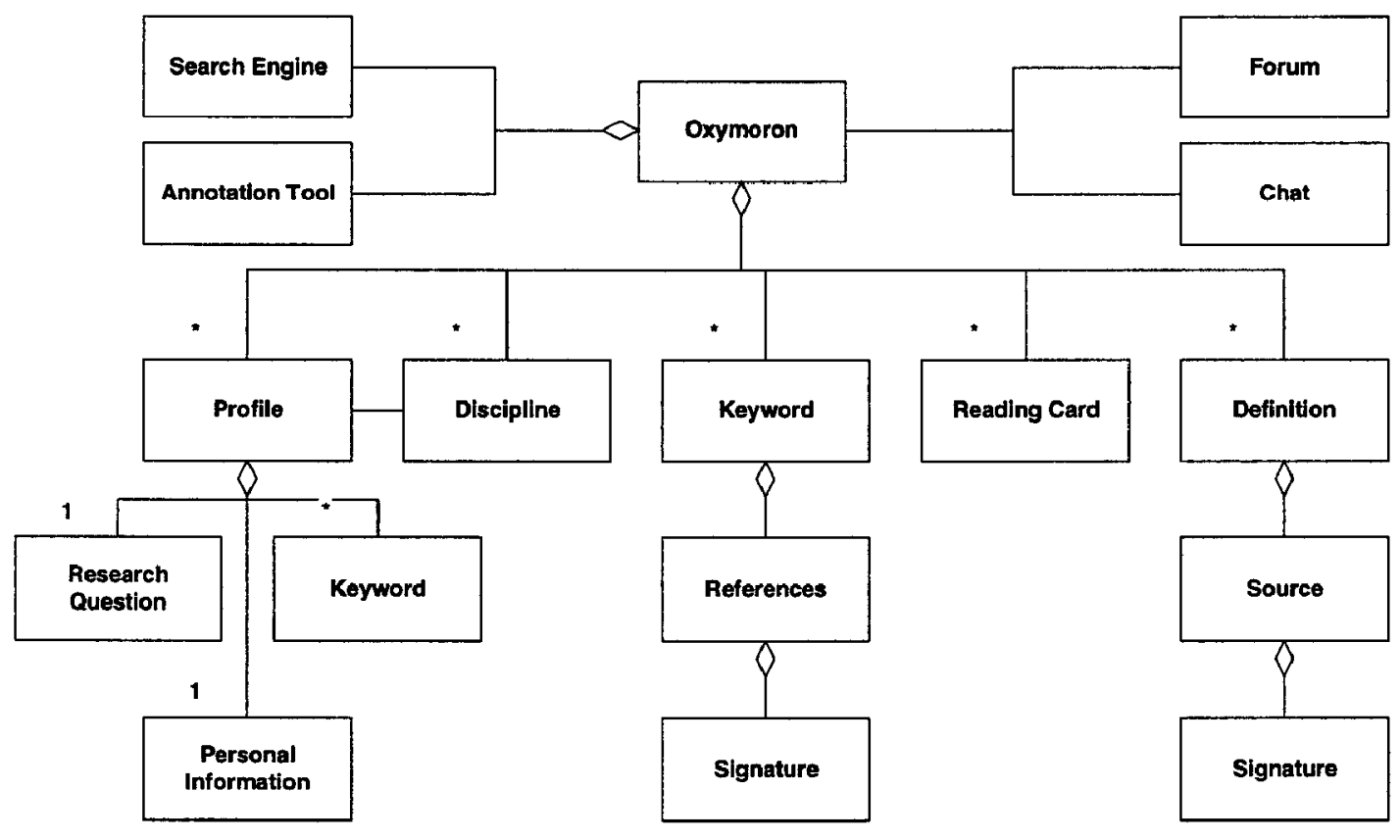

Figure 3. Overall Structure of Oxymoron 


\section{Students}

Who is the ideal Oxymoron user? In principle, every adult student engaged in a process that requires reading. In reality, an Oxymoron user is the social science student who

- has a computer and is able to type,

- is connected to the World Wide Web at home,

- perceives the need for sharing knowledge, that is to say, is ready to formalize and separate him/herself his/her personal work with the goal of accessing a great amount of shared work.

\section{STRUCTURE AND FUNCTIONALITY}

\section{Overall Structure}

Figure 3 shows the main elements that compose Oxymoron. We can identify the following components:

- The profiles contain the description of all the people registered in Oxymoron.

- The Keywords lead to the references.

- The Definitions contain definitions of terms that are added by the users. Each definition must be referenced by the source from which it was obtained (usually a book, dictionary encyclopedia etc).

- The reading cards are the main knowledge repository within Oxymoron and are explained later in this section.

The forum and chat components are standard communication tools available to Oxymoron users. These tools allow some degree of collaboration and tutoring to take place in between face-to-face meetings.

\section{Reading Cards}

The structure of a reading card is shown in figure 4. As you can see, it contains the standard elements found in a book such as the title, summary, table of contents, author bibliography, and biography. The two other elements are external to the book itself and are the critiques of the book, which may come from any other source, and the collection of reading notes.

The heart of a reading card is this collection of notes which are the actual quotations containing the most important ideas as viewed by the user who entered them. Each note contains 3 fields:

1. The keywords or themes the quote is associated with

2. The page number where the note is located

3. The actual quote extracted, as is, from the book

Each reading card has a signature that leads to the person who created it. Each reading note also has a signature that identifies its owner. The reason for this is that multiple users can add notes to an existing card. Thus the collection of notes is not the property of any one person but is, potentially, the collective work of many people. Attached to each note is a collection of annotations added by note owners or any other user of Oxymoron.
Reading notes are created manually by users. Therefore they are subjective. Two users will view different quotes as being the most important.

Reading notes should not be viewed as objective summaries of a book but rather as the personal view of the users who created them.

As reading notes are added to a reading card by different users, we may find the whole book in these notes. It could also be that the notes would concentrate on some chapters or pages of the book, in which case it will clearly show that these chapters or sections are really important, at least to the community of users who have created the notes.

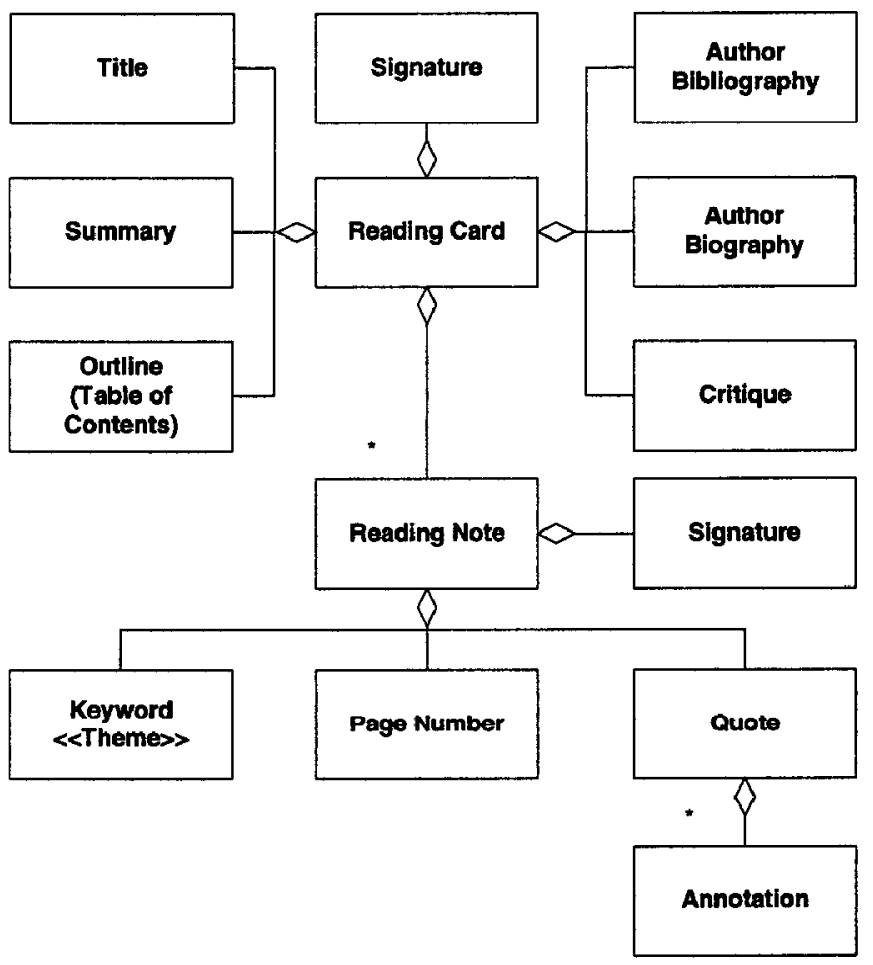

Figure 4. Structure of a Reading Card

\section{Global Search}

One of the essential components of Oxymoron is its powerful search facility. The search facility uses a search engine, which is tightly coupled with the underlying Informix database. It offers a search capability that enables users to find partial text strings within documents. Searches can be performed on all the contents of Oxymoron or limited to certain categories such as reading notes or bibliographies. The document conversion service, described below, helps too because it allows for the indexing of all documents regardless of their original format so that they are available to be searched.

\section{Support for Users' Existing Working Mode}

The first version of Oxymoron was a technology or developer centered version, developed directly from a set of specifications and user interface drawings with little or no concern to the way the user community was actually going to use the system. The second version was developed after 
the initial field tests indicated that users were having problems contributing meaningful quotes to the system.

Field investigation found that users were reluctant to use the forms that were designed to contribute quotes. The problem with the forms was not that they were badly designed, but that home users would not stay on-line for hours while they read their books and extracted quotes directly into the Oxymoron forms. Rather, they would build their quotes lists off-line with a word processor. Later, when connecting to Oxymoron they were faced with the tedious activity of copying and pasting the quotes from their Word processor into the forms and submitting them one quote at a time. The users balked and started sending their word processor documents to the support staff that went through this painful process on behalf of the users.

In addition, we also needed a solution that would allow users to add book summaries, table of contents and the like as nicely formatted HTML documents. Our user community made up of non-technical people, it was out of the question to ask them to write HTML code or even ask them to use other applications such as HTML editors. The less they had to learn the better.

We thus needed to offer a twofold solution:

1. Automatically insert quotcs into the database. HTML pages are later synthesized from the database content for display in a browser.

2. Accept word processor documents to construct the different sections of a reading card and convert them into HTML for display.

The introduction of these automatic conversion tools substantially simplified the way users added content to Oxymoron. As a result, we saw an immediate upsurge in the level of activity and content creation in Oxymoron.

Making the transition from the first version to the second, we removed the HTML forms and replaced them with forms accepting word processor files only. Thus, the use of a word processor to add information into Oxymoron was made mandatory. This, later, was revealed to be a limitation and we now plan to have both HTML forms and word processor forms in the next version.

\section{Support for Offline Work}

Retrospectively, we found that this new functionality and user interface also allowed us to easily support mobile users. It is very simple to add material to Oxymoron since users can create or edit their reading notes and other material on their notebook computers in the plane or train and later upload the files when they connect to the Internet.

\section{USER INTERFACE}

When entering Oxymoron, users are presented with a vertical navigation bar in the left frame. This bar gives access to all of the main Oxymoron sections: First the Oxymoron profile book (or yellow pages), then the reading cards, the keywords and references, the definitions and disciplines and finally the tools (search engine, chat room, forum).

\section{Profiles}

When a new user first enters Oxymoron, they are requested to fill out their profile. The profile is one of the central elements in Oxymoron because it allows people to get to know each other. The central piece of a profile entry is the research question the user is working on and the keywords associated with the person's work. These entries give some indication to other users about information that may be found in Oxymoron and the keywords needed to find it.

\section{Reading Cards}

The user can select to browse ("consulter") the reading cards, which is the most used feature, or to add a reading card. When browsing the reading cards, the user is presented with the list of cards available in Oxymoron sorted by author.

Clicking on the title of the book brings up the corresponding reading card. The book summary is displayed and above it the reading card navigation bar (figure 5). This bar gives access to the different sections of a reading card: the author biography and bibliography, the table of contents, the quotes (notes de lecture), and critiques. The biography, bibliography, and table of contents headings are followed by a browse ("consulter") or add ("ajouter") link depending on whether a user already filled out the section. The quotes and critiques sections are followed by a browse ("consulter") link is the section has any content and an add ("ajouter") button because their content is always evolving and can be added to.

[ biographie: consulter bibliographie: ajouter plan:
consulter notes de lecture: consulter/ ajouter
critique(s): ajouter]

Figure 5. Reading card navigation bar

\section{Quotes}

The heart of the Oxymoron knowledge repository is the collection of quotes. When the user chooses to browse the quotes, he or she is presented with a table where each line contains a quote (figure 6). Each quote carries a signature composed of the name of the person who added the quote along with the date when the quote was added or modified. The name of the person is a link to the person's profile entry in the Oxymoron profile book. The person browsing the quotes can immediately see the profile of the person who added a quote, as well as the thesis they are working on, the research question they are preoccupied with, etc. This is an essential functionality that allows people to link to one another. The owner of the quote (i.e. the person who added the quote) also has a "modify" link available. This allows him or her to make changes to each quote independently.

An annotation link is also available. It allows Oxymoron users to comment on any quote - be they the owners of quote or not (see Quotes Annotations). 


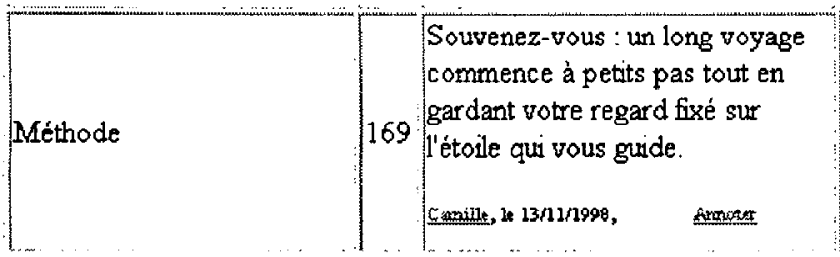

Figure 6. Example of a quote

\section{Quotes Annotations}

The rules of Oxymoron state that quotes must be the exact excerpts of the textbook. Users are not allowed to enter their own views in a quote. However, with the integration of the annotation service, we can offer users the ability to comment on a quote without changing the original. Within the cell of each quote there is, initially, an "annotate" link ("Annoter") (figure 6). When the user follows this link, the annotation service displays the quote within its annotation form (figure 7). This form allows the user to view other people's annotations and add their own. The annotation service supports annotations of type text, audio and video. Users can annotate a quote with the audio or video track of an interview of the author.

\begin{tabular}{l} 
Fin des années 60 . Une vingtaine de personnes, \\
dont Jacques Robin, Henri Atlan, Jacques Attali, \\
Henri Labonit, Edgar Morin, Michel Serres \\
\hline Texte à annoter: Fin des années 60 \\
Le texte doit compter au moins 2 caractères de séparation, \\
lrars:Furnut telle" srais pas "de lrarrsurnter".I1 y a aussi ur \\
Pourquoi est-ce important ? \\
Annoter
\end{tabular}

Figure 7. A quote within the annotation form

Once an annotation has been added to a quote, the quote is displayed with its annotation set (figure 8) and an annotated quote link ("citation annotée") is added to the quote. Users can choose to relate only to the exact quotes and ignore the attached annotations or they can browse the annotations by following this link.

\begin{tabular}{|c|c|c|}
\hline \multicolumn{3}{|c|}{ Note de lecture avec annotations } \\
\hline Thèmes & \begin{tabular}{|l}
$\mathrm{n}^{0}$ \\
page
\end{tabular} & Citations \\
\hline $\begin{array}{l}\text { Le } \\
\text { Groupe } \\
\text { des Dix }\end{array}$ & 36 & $\begin{array}{l}\text { Fin des années [1] 60. Une vingtaine } \\
\text { de personnes, dont Jacques Robin, } \\
\text { Henri Atlan, Jacques Attali, Henni } \\
\text { Laborit, Edgar Morin, Michel Serres }\end{array}$ \\
\hline 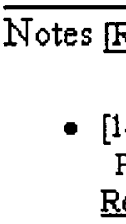 & 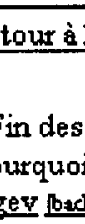 & $\begin{array}{l}\text { ensemble des notes]: } \\
\text { années } 60 \text { ] } \\
\text { est-ce important? }\end{array}$ \\
\hline
\end{tabular}

Figure 8. An annotated quote

\section{ARCHITECTURE AND IMPLEMENTATION}

Oxymoron is a multi-tier, distributed system. The main Web server, database, annotation service, text search engine, and IRC server are deployed on a Unix server. The document conversion service is deployed on a PC running Windows NT and IIS 4.0 (figure 9).

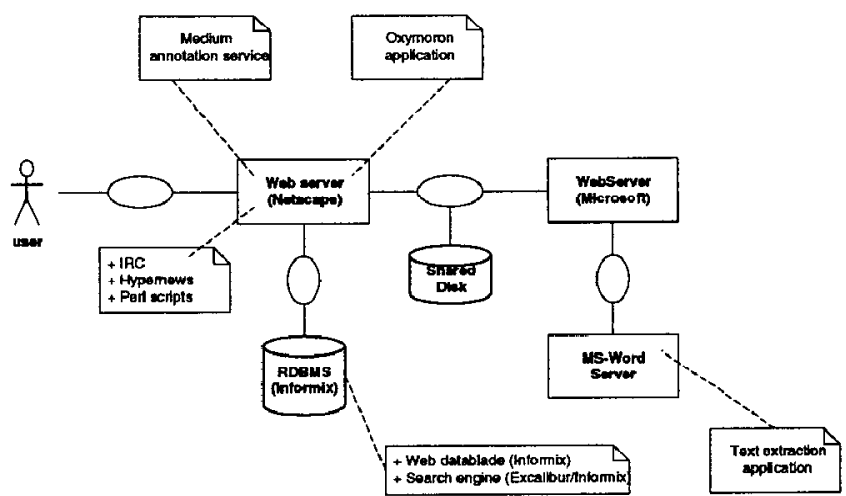

Figure 9. Overall Architecture

\section{Word Processing Integration}

As explained above, we integrated word processors and more specifically Microsoft Word into Oxymoron for two different tasks:

1. To insert quotes into the database, we developed a tool to automatically extract text from Word processors tables and insert them into the database

2. To collect summaries, table of contents, bibliographies, and in general any piece of text of some length, we developed an automatic Word to HTML conversion service

The following is an overview of the technologies we used for that integration

Automatic Word Processor to HTML Conversion Service We use the MS-Word ActiveX component to implement the conversion service. 


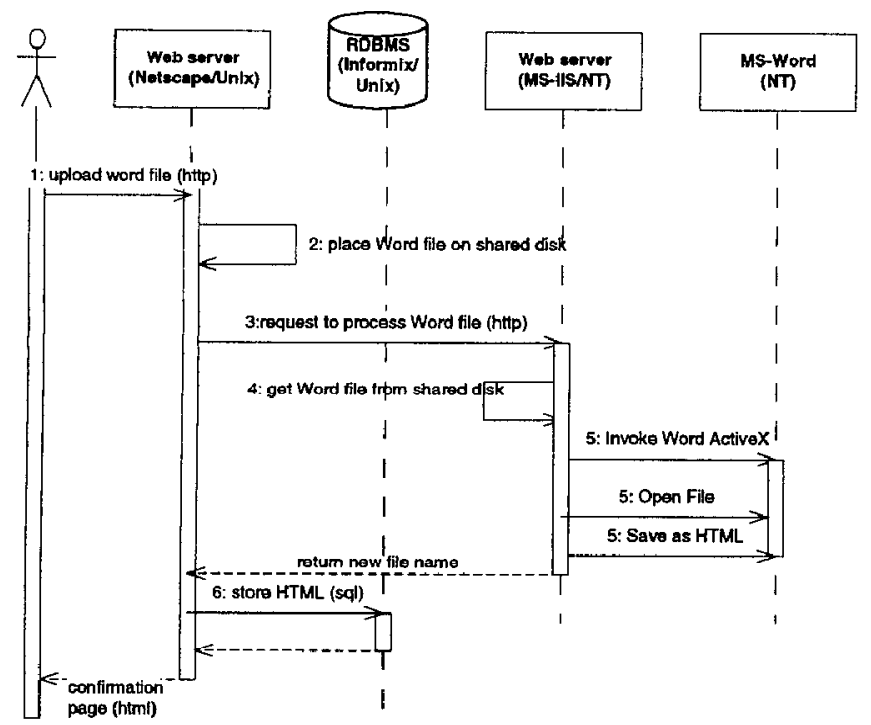

Figure 10. HTML Conversion scenario

Automatically converting a document of a format supported by MS-Word is actually as simple as instantiating a Microsoft Word application component, instructing it to open the desired file, and save it as HTML. The above processing can be done from any development platform that supports ActiveX, such as Active Server Pages and Visual Basic.

The main Web site hosting Oxymoron resides on a Unix server. Since we could not run Microsoft Word on that platform, we needed a way of linking the Windows and Unix platforms:

1. HTTP allowed us to invoke requests for conversion from the Unix machine to the Windows machine

2. A common disk space is shared between the 2 platforms through the institute LAN without having to transport the documents back and forth through HTTP

The conversion service was deployed on a Windows NT machine running an IIS Web server and MS-Office 97. Prior to invoking the conversion service, a PERL script on the Unix machine saves the incoming file on the shared disk space (figure 9). The Unix machine uses the service through an HTTP invocation of an ASP file. The file name to process is given as a parameter of the ASP invocation. The ASP file calls the MS-Word ActiveX component and requests that the file be opened and then saved as HTML.

The conversion operation is triggered when the user clicks the Upload button in one of the many Oxymoron forms that accept word processor files as input (creation of a reading card table of content for example). After having specified the local path of a document. The document is first saved in a BLOB in the Informix database and then in a file on the shared disk space. The conversion ASP file is called and, upon completion, the resulting HTML file is stored in the database and indexed so that it can be searched for (figure $10)$.

\section{Modifying a Document}

As the original document is saved in a BLOB in the database, we simply send it back to the user when the user wants to modify the document. The document is sent with a MIME type set to application/msword so that MS-Word is launched on the user's machine and the requested document is opened. While the document is loaded, the "modify document" form is displayed in the browser window. To complete the modification task the user needs to save the document locally and upload it again to the server through the "modify document" form.

\section{Supported Document Formats}

Using MS-Word as a document converter doesn't mean that the only file format we support is MS-Word. In fact we support any file format that MS-Word supports. This includes popular formats such as Rich Text File (RTF), Word Perfect 5.x and 6.x and text files. We also support Macintosh MS-Word files.

\section{Insertion of Quotes in the Database}

The process of inserting quotes is somewhat similar to the HTML conversion in that the uploaded file is saved on the shared disk space and the Perl script on the Unix server calls an ASP file on the NT machine. The ASP file, however, processes the files quite differently. It assumes that the Word document contains a table with 3 fields in each row. The structure of the table is fixed and is displayed below:

\begin{tabular}{|l|l|l|}
\hline Theme & Page Number & Quote \\
\hline
\end{tabular}

The text is extracted from the cells of the table and each row is sent back to the Unix machine by invoking an HTTP request that inserts the cells into the database. The process repeats as long as there are rows in the table.

\section{Modifying Quotes}

Modifying quotes is as simple as changing any other word processor originated document. Here, only the text of the quote is sent back to the user.

\section{Annotation Service Integration}

In parallel with the Oxymoron project we developed Medium, a Web based fine-grained annotation tool [12] that we converted into an annotation service that can be accessed through HTTP requests (figure 9). When the user clicks on the annotate link associated with a quote, the annotation service is called with the text of the quote as a parameter. The annotation server sends back an HTML page containing the requested quote together with its annotations. This HTML page contains links that enable the user to explore the annotations and modify them if the user is the author of the annotations. 


\section{CONCLUSIONS}

Oxymoron is an efficient and robust World Wide Web application that supports a pedagogical method for adult education in the field of the social sciences and palliative care. It is built on an original architecture linking multiple technological platforms to lower the barrier of entry and allow desktop integration with the World Wide Web.

Students at AFXB and UCSDR tested Oxymoron during the last year. Even though the second version of Oxymoron supports the users' way of working much better, it was not systematically used by the students. We attribute this to 2 main causes:

- Lack of integration of Oxymoron into the curriculum

- Psychological barriers to the use of a new tool

As described in [16], a tool such as Oxymoron cannot be successfully introduced in an organization without a global rethinking of the business processes and the fit of the tool to these processes. Hence, Oxymoron should be an integral part of the curriculum and it should match, more closely, the users' way of creating reading cards, as well as educators' requirements. We now have a commitment by IKB to fully integrate, with adequate tutoring, Oxymoron into several of next year's curricula and we are in the phase of restructuring and improving Oxymoron following comments from users and educators from a number of institutions where Oxymoron was presented. We also want to proceed with an evaluation of its usage patterns and the barriers to its more frequent use. We intend to use contextual inquiry techniques [9] to understand how users use Oxymoron in their homes.

We intend to pursue the development of Oxymoron in the following directions:

- To help Oxymoron users find their way within a multi-disciplinary knowledge repository, we are considering automatically cross referencing all keywords to their, potentially, multiple definitions and references.

- Over time we will face the problem of visualizing massive amounts of quotes, reading cards, keywords etc. We need to move beyond simply displaying lists of reading notes, keywords, annotations etc. We are exploring the feasibility of offering a concept map visualization tools that will help users to navigate within the knowledge repository.

- We are looking into offering information fetching services through the use of intelligent agents that will collect information on the Web on behalf of Oxymoron users in users specified interest areas.

While Oxymoron is used today only in the social science and health care fields it can be used in a technical research context as well in order to capitalize knowledge gained through reading conference and journal articles as well as books.

The Oxymoron main page is available, on the Web, at http://sgwww.epfl.ch/UF/Oxymoron.

\section{REFERENCES}

1. Ackerman, M. (1994) Augmenting the Organizational Memory: A Field Study of Answer Garden, Proceedings of CSCW'94, R. Furuta and C. Neuwirth (Eds), The Association for Computing Machinery, New York, pp. 243-252.

2. Bush, V., As We May Think, The Atlantic Monthly, July 1945.

3. Carre, P., Moisan, A., Poisson, D., L'auto-formation, Puf, Paris, 1997.

4. Conklin, J., Designing Organizational Memory: Preserving Intellectual Assets in a Knowledge Economy, http://www.gdss.com/dom.htm.

5. Davies, J., Stewart, S., Weeks, R., Knowledge Sharing over the World Wide Web, Proceedings of WebNet 98 , (AACE, Charlottesville, VA, 1998).

6. Desroche, H., Entreprendre d'apprendre. Apprentissage 3, Ed. Ouvrières, Paris, 1990.

7. D'Souza, D.F. and Wills A.C., Objects, components and Frameworks With UML: The Catalysis Approach. Addison-Wesley Object Technology Series, AddisonWesley, 1998.

8. Eco, U., Come si fa una tesi di laurea. Le materie umanistiche. Milano, Bompiani, 1980.

9. Engelbart, D. C., Toward High-Performance Organizations: A Strategic Role for Grouware in Proceedings of GroupWare '92, (San Jose, CA, August 1992), Morgan Kaufmann, San Francisco, CA.

10. Holtzblatt, K., Hugh, B., "Contextual Design: A Customer-Centered Approach to System Designs", Morgan Kaufman, San Francisco, CA, 1997.

11. Hruby, P., Structuring Specification of Business Systems with UML (with an Emphasis on Workflow Management Systems). in OOPSLA'98 Workshop: Business Object Design and Implementation IV: From Business Objects to Complex Adaptive Systems, (Vancouver, B.C. 1998).

12. Lapique, F., Regev, G., An Experiment Using Document Annotations in Education Proceedings of WebNet98, (AACE, Charlottesville, VA, 1998), 539544

13. Lévy, P., L'Intelligence collective. Pour une anthropologie du cyberespace, La Découverte, Paris, 1994.

14. Lévy, P., Cyberculture. Rapport au Conseil de l'Europe, Odile Jacob, Paris, X \& XI, 1997, pp.187. 213. 
15. Linard, M., Des machines et des hommes. Apprendre avec les nouvelles technologies, Ed. Universitaires (Savoir et Formation), Paris, 1990.

16. Markus, L., Keil, M., If We Build It, They Will Come: Designing Information Systems That People Want to Use, Sloan Management Review, Summer 1994, pp. 11-25.

17. Morin, E., Introduction à la pensée complexe, ESF, Paris, 1990.

18. Nonaka, I., Takeuchi, H., The Knowledge Creating Company, Oxford University Press, New York, NY, 1995.
19. Object Management Group, UML Specification, http://www.omg.org/techprocess/meetings/schedule/Te chnology_Adoptions.html\#tbl_UML_Specification, 1997.

20. Perriault, J., "Apprendre à distance" in Sciences Humaines HS n ${ }^{\circ}$ 16: La COMMUNICATION, Etat des savoirs. March-April 1997, 68-71.

21. Quivy, R., Campenhoudt, L., Manuel de recherches en sciences sociales, Dunod, Paris, 1995.

22. Serres, M., et al. Rapport de mission sur l'Université à Distance. doc. Multigr, Paris, 1992. 